\title{
A Microwave and $A b$ Initio Quantum Chemical Study of Intramolecular Hydrogen Bonding and Conformational Properties of 2-(Methylthio)ethanol
}

\author{
K.-M. Marstokk, Harald Møllendal ${ }^{\star}$ and Einar Uggerud \\ Department of Chemistry, The University of Oslo, P.O. Box 1033 Blindern, N-0315 Oslo 3, Norway
}

\begin{abstract}
Marstokk, K.-M., Møllendal, H. and Uggerud, E., 1989. A Microwave and Ab Initio Quantum Chemical Study of Intramolecular Hydrogen Bonding and Conformational Properties of 2-(Methylthio)ethanol. - Acta Chem. Scand. 43: 26-31.

The microwave spectra of $\mathrm{CH}_{3} \mathrm{SCH}_{2} \mathrm{CH}_{2} \mathrm{OH}$ and $\mathrm{CH}_{3} \mathrm{SCH}_{2} \mathrm{CH}_{2} \mathrm{OD}$ have been investigated at $0^{\circ} \mathrm{C}$. One conformer with all-gauche atomic arrangements, denoted $g G G$, was assigned and shown to be at least $3 \mathrm{~kJ} \mathrm{~mol}^{-1}$ more stable than any other rotameric form of the molecule. This rotamer is stabilized with an intramolecular hydrogen bond formed between the hydroxyl group hydrogen atom and the sulfur atom. $A b$ initio quantum chemical calculations at the 3-21 G level have been made for four selected conformations whose structures were fully optimized. These calculations predict the $g G G$ conformer to be the more stable, in agreement with the microwave findings.
\end{abstract}

Ethanol derivatives of the form $\mathrm{XCH}_{2} \mathrm{CH}_{2} \mathrm{OH}$ are capable of forming intramolecular hydrogen bonds in cases where $\mathrm{X}$ is an electronegative atom or group. Many such compounds have been studied by microwave (MW) spectroscopy in recent years. These studies include $\mathrm{X}=\mathrm{F},{ }^{1} \mathrm{Cl},{ }^{2}$ $\mathrm{Br},{ }^{2} \mathrm{C} \equiv \mathrm{N},{ }^{3} \quad \mathrm{OH},{ }^{4} \quad \mathrm{NH}_{2},{ }^{5} \quad \mathrm{SH}_{2}{ }^{6} \quad \mathrm{HC}=\mathrm{CH}_{2},{ }^{7} \mathrm{C} \equiv \mathrm{C}-\mathrm{H},{ }^{8}$ $\mathrm{OCH}_{3},{ }^{9} \mathrm{NH}\left(\mathrm{CH}_{3}\right),{ }^{10} \mathrm{CH}_{2}-\mathrm{CH}_{2}-\mathrm{N}^{11}$ and $\mathrm{N}\left(\mathrm{CH}_{3}\right)_{2}{ }^{12}$ In all these molecules, one conformer, or in the cases of $\mathrm{HOCH}_{2} \mathrm{CH}_{2} \mathrm{OH}^{4 \mathrm{~d}}$ and $\mathrm{HOCH}_{2} \mathrm{CH}_{2} \mathrm{NH}\left(\mathrm{CH}_{3}\right),{ }^{10}$ two rotamers, with heavy-atom gauche atomic arrangements and internal hydrogen bonds have been found to predominate in the gaseous state. In only one of these compounds, namely $\mathrm{HSCH}_{2} \mathrm{CH}_{2} \mathrm{OH},{ }^{6}$ has a sulfur atom participated in intramolecular hydrogen bonding as proton acceptor. This molecule was found to adopt the all-gauche conformation with the hydroxyl group as proton donor and the thiol group as acceptor. No further conformations were identified for free $\mathrm{HSCH}_{2} \mathrm{CH}_{2} \mathrm{OH}^{6}{ }^{6}$

2-(Methylthio)ethanol was chosen for study because we wanted to investigate the ability of the sulfur atom to act as acceptor for internal hydrogen bonds, as well as to extend the list of 2-substituted ethanol derivatives for which this interaction is a major factor in determining the conformational properties of the molecule.

In $\mathrm{CH}_{3} \mathrm{SCH}_{2} \mathrm{CH}_{2} \mathrm{OH}$ there are three internal rotation axes; consequently, as many as 17 all-staggered conformations are possible for this compound. Fig. 1 shows four selected rotamers. These conformations are believed to be the four with the lowest energies for the following reasons: The $g G G$ and $g G A$ rotamers each possess an intramolecular hydrogen bond, just as in the case of $\mathrm{HSCH}_{2} \mathrm{CH}_{2} \mathrm{OH}{ }^{6}$

\footnotetext{
* To whom correspondence should be addressed.
}

Both $g G G$ and $g G A$ on the one hand were therefore expected to be more stable than $a A G$ and $a A A$ on the other, because $a A G$ and $a A A$ lack this stabilizing interaction.

The only conformational difference between the hydrogen-bonded $g G G$ and $g G A$ forms is the orientation of the methyl group, which is gauche to the $\mathrm{C}-\mathrm{C}$ bond in $g G G$ and anti to the same bond in $g G A$. The same conformational difference as that between $g G G$ and $g G A$ is also found for $\mathrm{CH}_{3} \mathrm{SCH}_{2} \mathrm{CH}_{3}{ }^{13}$ The enthalpy difference between the gauche and anti conformers of $\mathrm{CH}_{3} \mathrm{SCH}_{2} \mathrm{CH}_{3}$ is only $0.13(20) \mathrm{kJ} \mathrm{mol}^{-1}$, with the gauche rotamer being the slightly more stable. ${ }^{13 a}$ If conformational properties were<smiles>CS[IH]C</smiles>

gGG<smiles>CSC(=O)O</smiles>

aAG
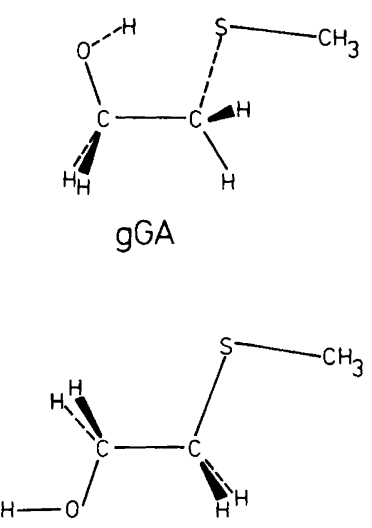

$a A A$
Fig. 1. Four selected conformations of $\mathrm{CH}_{3} \mathrm{SCH}_{2} \mathrm{CH}_{2} \mathrm{OH}$. Intramolecular hydrogen bonding is possible in $g G G$ and $g G A$, while this interaction is not possible in $a A G$ and $a A A$. Only the all-gauche rotamer $g G G$ was identified in the MW spectrum. 
transferable, it would thus be expected that the $g G G$ and $g G A$ rotamers would have very similar energies, by analogy with the findings for $\mathrm{CH}_{3} \mathrm{SCH}_{2} \mathrm{CH}_{3}$. This, however, was not found to be the case. It turned out in the course of this work that there is a remarkable preference for $g G G$, just as for the all-gauche counterpart of $\mathrm{HSCH}_{2} \mathrm{CH}_{2} \mathrm{OH}{ }^{6}$

It was also believed worthwhile to examine the spectrum for evidence of two of the heavy-atom anti conformations of the title molecule, which perhaps might have sufficiently low energies to be observable. The best candidates for such a search are presumably the $a A G$ and $a A A$ conformations shown in Fig. 1. There is of course no internal hydrogen bond in any of these two forms. Moreoyer, the $\mathrm{O}-\mathrm{H}$ bond is anti to the $\mathrm{C}-\mathrm{C}$ bond in both $a A G$ and in $a A A$. This conformation for the hydroxyl group was selected instead of gauche because the anti conformer of ethanol is $2.9(2) \mathrm{kJ}$ mol $^{-1}$ more stable than the gauche. ${ }^{14}$ The methyl group conformation is gauche in $a A G$ and anti in $a A A$. Neither $a A G$ nor $a A A$ were assigned in this work, presumably because they have higher energies than the identified $g G G$ conformer.

$A b$ initio computations are often found to mimic gasphase conformational equilibria rather well. It was therefore decided to perform such calculations for the four selected conformations shown in Fig. 1. These computations also predicted the $g G G$ conformer to be considerably more stable than the other three conformations depicted in Fig. 1, as will be shown below.

\section{Experimental}

Experimental conditions. A commercial sample of 2(methylthio)ethanol was employed in this work. The sample was purified by gas chromatography before use. The absorption cell was cooled to about $0^{\circ} \mathrm{C}$. Lower temperatures could not be used due to insufficient vapour pressure of the compound. The pressure was about $2 \mathrm{~Pa}$ when the spectra were recorded. The spectrometer used is an improved version of the one described briefly in Ref. 15, employing klystrons as radiation sources. The radio frequency-microwave frequency double resonance technique (RFMWDR) was used as described in Ref. 16, employing the equipment mentioned in Ref. 17. The $26.5-38.0 \mathrm{GHz}$ spectral region was studied extensively. Some measurements were also made in the $18-24 \mathrm{GHz}$ range. The deute- riated species $\mathrm{CH}_{3} \mathrm{SCH}_{2} \mathrm{CH}_{2} \mathrm{OD}$ was produced by exchange with heavy water in the absorption cell. The degree of deuteriation obtained in this way was roughly $50 \%$.

Method of calculation. The $a b$ initio quantum chemical computations were performed using the GAMESS ${ }^{18}$ prograin package. The program used in the present calculations is a revised version prepared by $\mathrm{M}$. W. Schmidt of North Dakota State University and S. Elbert of Iowa State University. The computations were made using a FPS-164 computer. The basis set 3-21 G (Ref. 19) was chosen, and the geometries of the four conformations of Fig. 1 were optimized at the Hartree-Fock theoretical level by calculating the analytical energy gradients. More elaborate basis sets could not be used for financial reasons.

\section{Results}

Predictions. $A b$ initio calculations are helpful in making predictions about energy differences between various conformations, as well as their dipole moments and structures. In Table 1, energy differences between the four conformations as well as principal axis dipole moment components obtained from the ab initio computations are collected. It is seen that the $g G G$ conformation is predicted to be more than $5 \mathrm{~kJ} \mathrm{~mol}^{-1}$ more stable than any other of the four forms for which computations were made. This conformer is also predicted to possess sizable dipole moment components along all three principal inertial axes (Table 1).

The $a b$ initio optimized structural parameters given in Table 2 appear to be reasonable, apart from the $\mathrm{C}-\mathrm{S}$ bond lengths and the $\mathrm{C}-\mathrm{C}-\mathrm{S}-\mathrm{C}$ dihedral angles of the $g G G$ and $a A G$ conformations. The $\mathrm{C}-\mathrm{S}$ bond lengths are roughly $8 \mathrm{pm}$ greater, while the $\mathrm{C}-\mathrm{C}-\mathrm{S}-\mathrm{C}$ dihedral angles are approximately $10^{\circ}$ smaller than the substitution values found for the corresponding bond lengths and dihedral angle in gauche $\mathrm{CH}_{3} \mathrm{SCH}_{2} \mathrm{CH}_{3}{ }^{13 \mathrm{~d}}$ (see also Table 7). This kind of overestimation of $\mathrm{C}-\mathrm{S}$ bond lengths is known to occur when use is made of the $3-21 \mathrm{G}$ basis set. ${ }^{20}$

The rather long bond lengths and small $\mathrm{C}-\mathrm{C}-\mathrm{S}-\mathrm{C}$ dihedral angles obtained by the theoretical calculations in the cases of $g G G$ and $a A G$ will predict rotational constants which will be too small. Therefore, preliminary rotational constants were computed by combining structural parameters for related compounds (see Table 7). Principal axis

Table 1. Relative energies and principal axis dipole moment components calculated by ab initio for the four conformations of Fig. 1.

\begin{tabular}{lllll}
\hline Conformation & $\begin{array}{l}\text { Relative } \\
\text { energy } / \mathrm{kJ} \mathrm{mol}^{-1}\end{array}$ & \multicolumn{3}{l}{ Dipole moment comp. $/ 10^{-30} \mathrm{C} \mathrm{m}$} \\
\cline { 4 - 5 } & & a-axis & $b$-axis & $c$-axis \\
\hline$g G G$ & 0.0 & 5.3 & 7.9 & 2.6 \\
$g G A$ & 5.2 & 6.6 & 5.9 & 0.5 \\
$a A G$ & 9.2 & 2.6 & 7.3 & 3.5 \\
$a A A$ & 11.6 & 1.4 & 0.4 & 0.0 \\
\hline
\end{tabular}


Table 2. Selected optimized structural parameters obtained by $a b$ initio calculations for the four conformations shown in Fig. 1

\begin{tabular}{lrrrr}
\hline & $g G G$ & $g G A$ & \multicolumn{1}{c}{$a A G$} & \multicolumn{1}{c}{$a A A$} \\
\hline Bond lengths/pm & & & & \\
$\mathrm{S}^{-} \mathrm{CH}_{3}$ & 188.7 & 188.5 & 188.8 & 188.4 \\
$\mathrm{~S}-\mathrm{CH}_{2}-$ & 189.1 & 189.2 & 188.3 & 188.7 \\
$\mathrm{O}-\mathrm{C}$ & 143.3 & 143.3 & 144.3 & 144.1 \\
$\mathrm{C}-\mathrm{C}$ & 152.7 & 152.7 & 151.9 & 152.2 \\
& & & & \\
Bond angles ${ }^{\circ}$ & & & & \\
$\angle \mathrm{C}-\mathrm{S}-\mathrm{C}$ & 100.2 & 100.2 & 100.3 & 99.8 \\
$\angle \mathrm{C}-\mathrm{C}-\mathrm{S}$ & 111.7 & 108.8 & 112.0 & 108.7 \\
$\angle \mathrm{O}-\mathrm{C}-\mathrm{C}$ & 111.7 & 112.2 & 105.4 & 108.7 \\
& & & & \\
Dihedral angles ${ }^{\circ}$ & & & & \\
$\angle \mathrm{O}-\mathrm{C}-\mathrm{C}-\mathrm{S}$ from syn & 61.5 & 68.7 & 179.4 & 180.0 \\
$\angle \mathrm{C}-\mathrm{C}-\mathrm{S}-\mathrm{C}$ from anti & 103.1 & 4.6 & 100.8 & 0.0 \\
$\angle \mathrm{H}-\mathrm{O}-\mathrm{C}-\mathrm{C}$ from syn & 57.3 & 63.7 & 177.4 & 180.0 \\
\hline
\end{tabular}

Table 4. Microwave spectrum of the $g G G$ conformer of $\mathrm{CH}_{3} \mathrm{SCH}_{2} \mathrm{CH}_{2} \mathrm{OH}$.

\begin{tabular}{lll}
\hline Transition & $\begin{array}{l}\text { Observed } \\
\text { frequency } / \mathrm{MHz}\end{array}$ & $\begin{array}{c}\text { Obs. }- \text { Calc. } \\
\text { frequency } / \mathrm{MHz}\end{array}$ \\
\hline $5_{0,5} \leftarrow 4_{0,4}$ & 22861.90 & 0.05 \\
$5_{1,4} \leftarrow 4_{1,3}$ & 23008.59 & -0.07 \\
$5_{1,5} \leftarrow 4_{1,4}$ & 22731.17 & -0.08 \\
$5_{2,3} \leftarrow 4_{2,2}$ & 22881.43 & -0.11 \\
$5_{2,4} \leftarrow 4_{2,3}$ & 22871.18 & -0.05 \\
$6_{0,6} \leftarrow 5_{0,5}$ & 27428.01 & -0.03 \\
$6_{1,5} \leftarrow 5_{1,4}$ & 27608.48 & 0.09 \\
$6_{1,6} \leftarrow 5_{1,5}$ & 27275.66 & 0.07 \\
$6_{2,4} \leftarrow 5_{2,3}$ & 27462.00 & 0.00 \\
$6_{2,5} \leftarrow 5_{2,4}$ & 27444.07 & 0.08 \\
$7_{0,7} \leftarrow 6_{0,6}$ & 31990.81 & -0.10 \\
$7_{1,6} \leftarrow 6_{1,5}$ & 32207.05 & 0.05 \\
$7_{1,7} \leftarrow 6_{1,6}$ & 31818.98 & 0.06 \\
$7_{2,4} \leftarrow 6_{2,3}$ & 32044.84 & 0.14 \\
$7_{2,5} \leftarrow 6_{2,4}$ & 32015.95 & 0.00 \\
$8_{0,8} \leftarrow 7_{0,7}$ & 36550.00 & 0.05 \\
$8_{1,7} \leftarrow 7_{1,6}$ & 36804.23 & -0.05 \\
$8_{1,8} \leftarrow 7_{1,7}$ & 36361.06 & -0.03 \\
$8_{2,6} \leftarrow 7_{2,5}$ & 36629.85 & -0.08 \\
$8_{2,7} \leftarrow 7_{2,6}$ & 36586.95 & -0.01 \\
\hline
\end{tabular}

${ }^{a} \pm 0.15 \mathrm{MHz}$. dipole moment components were predicted using the bondmoment method, ${ }^{21}$ which is often quite accurate in cases such as the present one. The results are summarized in Table 3. The total dipole moments of the four conformations of Fig. 1 can be calculated from the values shown in Tables 1 and 3. The total dipole moments predicted by the bond-moment method are roughly $20 \%$ smaller than those predicted using the ab initio method.

Spectrum. The spectrum of $\mathrm{CH}_{3} \mathrm{SCH}_{2} \mathrm{CH}_{2} \mathrm{OH}$ is very dense, with absorptions occurring every few $\mathrm{MHz}$ throughout the entire investigated $\mathrm{MW}$ region. It is also comparatively very weak. The strongest absorptions of the spectrum are the high- $K_{-1}$ pile-ups of the $a$-type $R$-branch transitions of the $g G G$ conformation. The ground-state $J=8 \leftarrow 7$ pile-up has a peak absorption coefficient of roughly $1.5 \times 10^{-7} \mathrm{~cm}^{-1}$. This is the strongest transition in the spectrum. The intensities of the resolved low- $K_{-1}$ lines of the $J=8 \leftarrow 7$ transitions corresponded to peak absorption coefficients of roughly $5 \times 10^{-8} \mathrm{~cm}^{-1}$.

Assignment. A search was first made for the $g G G$ form based on the predictions discussed above. This rotamer has a value for Ray's asymmetry parameter ${ }^{22}$ of $x \approx-0.97$. High- $K_{-1}$ pile-ups were predicted for the $a$-type $R$-branch transitions of this conformer. These pile-ups were readily observed since they are the strongest lines in the spectrum. They were also found very close to their predicted frequencies. Their assignments were confirmed by RFMWDR experiments. ${ }^{16}$ The low- $K_{-1}$ lines which are resolved from these pile-ups were found after some searching. They are listed in Table 4. The spectroscopic constants given in Table 5 were derived from the transitions listed in Table 4.

According to the predicted dipole moments in Tables 1 and 3 , the $g G G$ conformer would be expected to display $b$ and $c$-type transitions in addition to the $a$-type lines listed in Table 2. Extensive searches were made in an attempt to find these $b$ - and $c$-type transitions, but they were not identified, presumably because of the weakness and density of the spectrum. Without these $b$ - or $c$-type lines it is not possible to obtain an accurate value for the $A_{0}$ rotational constant, since $g G G$ is nearly a symmetrical top with $x=-0.975354$ and the ${ }^{a} R$-transitions of Table 2 are insufficient for an accurate determination of said constant in

Table 3. Predicted rotational constants and principal axis dipole moment components for the four conformations of Fig. $1 .^{a}$

\begin{tabular}{|c|c|c|c|c|c|c|}
\hline \multirow[t]{2}{*}{ Conformation } & \multicolumn{3}{|c|}{ Rotational constants / GHz } & \multicolumn{3}{|c|}{ Dipole moment comp. $/ 10^{-30} \mathrm{C} \mathrm{m}$} \\
\hline & $A$ & $B$ & $C$ & a-axis & $b$-axis & $c$-axis \\
\hline$g G G$ & 6.76 & 2.32 & 2.23 & 3.7 & 4.8 & 4.0 \\
\hline$g G A$ & 10.23 & 2.04 & 1.86 & 5.6 & 4.4 & 1.0 \\
\hline$a A G$ & 9.11 & 1.88 & 1.68 & 2.2 & 7.0 & 2.4 \\
\hline$a A A$ & 13.85 & 1.63 & 1.50 & 1.0 & 0.0 & 0.0 \\
\hline
\end{tabular}

a See text. 
Table 5. Spectroscopic constants for the ground vibrational states of the $g G G$ conformer of $\mathrm{CH}_{3} \mathrm{SCH}_{2} \mathrm{CH}_{2} \mathrm{OH}$ and $\mathrm{CH}_{3} \mathrm{SCH}_{2} \mathrm{CH}_{2} \mathrm{OD}$. $^{\mathrm{a}}$

\begin{tabular}{lll}
\hline Species & $\mathrm{CH}_{3} \mathrm{SCH}_{2} \mathrm{CH}_{2} \mathrm{OH}$ & $\begin{array}{l}\mathrm{CH}_{3} \mathrm{SCH}_{2} \mathrm{CH}_{2} \mathrm{OD} \\
\text { Number of transitions }\end{array}$ \\
R.m.s deviation $/ \mathrm{MHz}$ & 0.080 & 9 \\
& & 0.113 \\
$A_{0} / \mathrm{MHz}$ & $6762.7(76)$ & $6468(27)$ \\
$B_{0} / \mathrm{MHz}$ & $2315.0640(69)$ & $2280.037(21)$ \\
$C_{0} / \mathrm{MHz}$ & $2259.5705(69)$ & $2244.212(26)$ \\
$\Delta_{J} / \mathrm{kHz}$ & $2.028(48)$ & $2.03(18)$ \\
$\Delta_{J K} / \mathrm{kHz}$ & $-5.4(12)$ & $-6.1(24)$ \\
$x^{c}$ & -0.975354 & -0.983040 \\
\hline
\end{tabular}

${ }^{a} A$-reduction Ir-representation. ${ }^{23}$ Uncertainties represent one standard deviation. ${ }^{\circ}$ Further quartic centrifugal distortion constants were preset at zero. ' Ray's asymmetry parameter. ${ }^{22}$

such cases. Only two of Watson's centrifugal distortion constants $^{23}$ were used in the least-squares fitting of the spectroscopic constants ( $A$-reduction $I^{r}$-representation) due to the limited experimental data at hand.

Table 5 also contains the spectroscopic constants ${ }^{\S}$ for the deuteriated species $\mathrm{CH}_{3} \mathrm{SCH}_{2} \mathrm{CH}_{2} \mathrm{OD}$. This species was studied in order to establish beyond doubt the position of the hydroxyl group hydrogen atom. This atom cannot be located accurately by the use of Kraitchman's equations ${ }^{24}$ because the $A_{0}$ 's for the parent and deuteriated species are rather inaccurate (Table 5). However, the $B_{0}$ 's and $C_{0}$ 's for said species are very accurate and can be used to obtain unambiguous information concerning the position of the hydroxyl group hydrogen atom. From Table 5 it is seen that $B_{0}$ changes by $-35.03 \mathrm{MHz}$ and $C_{0}$ by $-15.36 \mathrm{MHz}$, respectively, upon substitution. The changes calculated using the plausible structure (see below) are $-36.55 \mathrm{MHz}$ and $-18.56 \mathrm{MHz}$, respectively. There is thus quite good agreement between experimental and calculated changes in $B_{0}$ and $C_{0}$ upon substitution. This is conclusive evidence that an intramolecular hydrogen bond exists in the preferred $g G G$ conformation of free 2-(methylthio)ethanol.

Vibrationally excited states. The ground-state transitions were accompanied by transitions belonging to several vibrationally excited states. Four of these were assigned. In two cases the low- $K_{-1}$ transitions were so strong that assignments could be made. Their spectroscopic constants are given in Table 6. It is presumed that these two excited states result from successive excitation of the torsion around the $-\mathrm{CH}_{2}-\mathrm{SCH}_{3}$ bond. In the two other cases only the pile-ups were assigned, and approximate values for $B_{\mathrm{v}}+C_{\mathrm{v}}$ of $4600.85(10) \mathrm{MHz}$ were determined for what is

\footnotetext{
${ }^{8}$ The transitions used to derive these constants, as well as the spectra of the vibrationally excited states, are available from the authors upon request, or from the Molecular Spectra Data Center, Bldg. 221, Room B 268, National Bureau of Standards, Gaithersburg, Maryland 20899, U.S.A., where they have been deposited.
}

Table 6. Spectroscopic constants for vibrationally excited states of the $g \mathrm{GG}$ conformer of $\mathrm{CH}_{3} \mathrm{SCH}_{2} \mathrm{CH}_{2} \mathrm{OH}^{a}$

\begin{tabular}{|c|c|c|}
\hline $\begin{array}{l}\text { Vibrational state } \\
\text { Number of transitions } \\
\text { R.m.s deviation } / \mathrm{MHz}\end{array}$ & $\begin{array}{l}\text { First ex. }-\mathrm{CH}_{2}-\mathrm{S} \\
\text { torsional vib. } \\
17 \\
0.128\end{array}$ & $\begin{array}{l}\text { Second ex. }-\mathrm{CH}_{2}-\mathrm{S} \\
\text { torsional vib. } \\
11 \\
0.182\end{array}$ \\
\hline$A_{v} / \mathrm{MHz}$ & $6765(11)$ & $6835(23)$ \\
\hline$B_{\mathrm{v}} / \mathrm{MHz}$ & $2323.717(13)$ & $2327.690(23)$ \\
\hline$C_{\mathrm{v}} / \mathrm{MHz}$ & $2264.786(11)$ & $2269.478(25)$ \\
\hline$\Delta_{l} / \mathrm{kHz}^{b}$ & $2.260(91)$ & $3.32(19)$ \\
\hline$\Delta_{J K} / \mathrm{kHz}$ & $-5.9(22)$ & $-14.1(34)$ \\
\hline$x^{c}$ & -0.973811 & -0.974501 \\
\hline
\end{tabular}

$a, b, c$ Comments as for Table 5.

presumed to be the third excited state of the same torsional mode. A value of $B_{\mathrm{v}}+C_{\mathrm{v}} \approx 4561.86(10) \mathrm{MHz}$ was found for the fourth pile-up which is presumed to be the first excited state of the $-\mathrm{CH}_{2}-\mathrm{CH}_{2}-$ torsional vibration. It is also possible that this is a low-frequency bending mode.

An accurate determination of the two torsional frequencies could not be made due to the weakness of the spectrum. However, the $-\mathrm{CH}_{2}-\mathrm{SCH}_{3}$ torsion is estimated to have a frequency of ca. $70 \mathrm{~cm}^{-1}$. This mode appears to be quite anharmonic, since the spectral shifts of the pile-up of successively excited states are not equidistant. The approximate sums of $B+C$ derived from the pile-ups are thus $4574.95 \mathrm{MHz}$ for the ground state, $4588.84 \mathrm{MHz}$ for the first excited torsional state, $4597.52 \mathrm{MHz}$ for the second, and $4600.85 \mathrm{MHz}$ for the third excited state of this torsional vibration.

The $-\mathrm{CH}_{2}-\mathrm{CH}_{2}-$ torsional vibration is estimated to have a frequency of ca. $130 \mathrm{~cm}^{-1}$. These two values for the two torsional vibrations are not very different from what have been observed by IR spectroscopy ${ }^{13 a}$ in condensed phases for ethyl methyl sulfide. The $a b$ initio values for these two torsional vibrations were computed to be $77 \mathrm{~cm}^{-1}$ and 157 $\mathrm{cm}^{-1}$, respectively. It has been noted that vibrational frequencies calculated with a 3-21 G basis are generally $5-10 \%$ too large. ${ }^{20}$

Searches for further conformations. As mentioned above, the hypothetical $g G A$ (Fig. 1) conformation was believed to be a good candidate to search for. The ab initio calculations (Table 1) predict this conformer to be $5.2 \mathrm{~kJ} \mathrm{~mol}^{-1}$ less stable than $g G G$. As can be seen in Tables 1 and 3, a rather large $\mu_{a}$ was predicted for this conformer, which was also predicted to be very prolate with $x \approx-0.95$. Easily identifiable pile-ups similar to those assigned for $g G G$ were thus predicted for $g G A$. Searches were made for these pile-ups using ordinary Stark effect spectroscopy as well as the RFMWDR technique. ${ }^{16}$ Moreover, $b$-type lines were also searched for since $\mu_{b}$ is predicted to be sizable (Tables 1 and 3), but $g G A$ was not found. 
Table 7. Plausible molecular structure ${ }^{a}$ (bond lengths in pm, angles in degrees) of $\mathrm{CH}_{3} \mathrm{SCH}_{2} \mathrm{CH}_{2} \mathrm{OH}$.

$\begin{array}{lccc}\text { Structural parameters kept fixed } \\ \mathrm{H}_{3} \mathrm{~S}-\mathrm{C} & 180.2^{b} & & \\ \mathrm{H}_{3} \mathrm{~S}-\mathrm{C} & 180.4^{d} & \angle \mathrm{C}-\mathrm{C}-\mathrm{S} & 114.7^{b} \\ -\mathrm{S}-\mathrm{CH}_{2}- & 180.6^{b} & \angle \mathrm{C}-\mathrm{C}-\mathrm{S} & 109.5^{d} \\ -\mathrm{S}-\mathrm{CH}_{2}- & 180.4^{d} & \angle \mathrm{C}-\mathrm{S}-\mathrm{C} & 100.2^{b} \\ \mathrm{C}-\mathrm{C} & 152.4^{b} & \angle \mathrm{C}-\mathrm{S}-\mathrm{C} & 99.0^{d} \\ \mathrm{C}-\mathrm{C} & 153.0^{d} & \angle \mathrm{O}-\mathrm{C}-\mathrm{C} & 112.5 \\ \mathrm{C}-\mathrm{O} & 141.5 & \angle \mathrm{H}-\mathrm{O}-\mathrm{C} & 104.0 \\ \mathrm{O}-\mathrm{H} & 95.0 & \angle \mathrm{H}-\mathrm{C}-\mathrm{C} & 109.47 \\ \mathrm{C}-\mathrm{H} & 109.3 & \angle \mathrm{H}-\mathrm{C}-\mathrm{S} & 109.47\end{array}$

Fitted $^{\theta}$

$\begin{array}{lr}\angle \mathrm{C}-\mathrm{C}-\mathrm{S}-\mathrm{C} & 113(3) \text { from anti } \\ \angle \mathrm{O}-\mathrm{C}-\mathrm{C}-\mathrm{S} & 61(3) \text { from syn }\end{array}$

(67(3)) from syn

Hydrogen bond parameters

$\begin{array}{lllrlr}\mathrm{H} \cdots \mathrm{S} & 271 & \angle \mathrm{O}-\mathrm{H} \cdots \mathrm{S} & 113 & \angle \mathrm{O}-\mathrm{H},-\mathrm{CH}_{2}-\mathrm{S}^{f} & 5 \\ \mathrm{O} \cdots \mathrm{S} & 321 & \angle \mathrm{H} \cdots \mathrm{S}-\mathrm{CH}_{2}- & 65 & \angle \mathrm{O}-\mathrm{H}, \mathrm{S}-\mathrm{CH}_{3}{ }^{\prime} & 104\end{array}$ $\angle \mathrm{H} \cdots \mathrm{S}-\mathrm{CH}_{3} \quad 98$

Sum of van der Waals radii ${ }^{g}$

H.S $\quad 305$

O‥S 325

a See text. ${ }^{b} g G G$ and $a A G$ conformations. ${ }^{c}$ Taken from Refs. $13 \mathrm{c}$ and $13 \mathrm{~d}$. ${ }^{\circ} g G A$ and $a A A$ conformations. ${ }^{\circ}$ See text. Dihedral angle. 'Angle between $\mathrm{O}-\mathrm{H}$ and $\mathrm{S}-\mathrm{C}$ bond. ${ }^{9}$ Taken from Ref. 25.

The bond-moment method ${ }^{21}$ is generally found to yield quite accurate dipole moments in cases such as the present molecule. It is therefore concluded that there must be a considerable energy difference between the $g G G$ and the hypothetical $g G A$ conformation, since the latter could not be identified. Conservative estimates lead us to conclude that $g G G$ is a least $3 \mathrm{~kJ} \mathrm{~mol}^{-1}$ more stable than the hypothetical $g G A$ form. This is in accord with the ab initio value of $5.2 \mathrm{~kJ} \mathrm{~mol}^{-1}$ (Table 1).

The two $\mathrm{O}-\mathrm{C}-\mathrm{C}-\mathrm{S}$ anti rotamers $a A G$ and $a A A$ were also searched for in vain. The $a b$ initio computations of Table 1 predict these two conformations to have considerably higher energies than the identified $g G G$ conformer.

Although the above assignments account for the strongest lines of the spectrum, there is a very large number of weak or very weak unassigned transitions left. Many of these are suspected to be high- $J Q$-branch transitions of the $b$ - or $c$-type varieties of the ground and vibrationally excited states of the identified $g G G$ conformer. Unfortunately, it was not possible for us to assign them, as mentioned above. The existence of small fractions of conformations other than $g G G$ is considered to be quite possible. However, intensity considerations lead us to conclude rather conservatively that $g G G$ must be at least $3 \mathrm{~kJ} \mathrm{~mol}^{-1}$ more stable than any other form of the molecule.

Structure. Rotational constants have been derived for only two isotopomers (Table 5). There are thus insufficient data to perform a complete structure determination for the $g G G$ conformer of 2-(methylthio)ethanol. Assumptions have to be made in order to derive important structural parameters. The $\mathrm{C}-\mathrm{C}-\mathrm{S}-\mathrm{C}$ and $\mathrm{O}-\mathrm{C}-\mathrm{C}-\mathrm{S}$ dihedral angles were selected for fitting, because they are chemically interesting and because the rotational constants depend strongly on these dihedral angles. The two dihedral angles were varied in steps of $1^{\circ}$, with the other structural parameters kept at the values shown in Table 7. The entries in this table have been selected from recent, accurate studies of closely related compounds. The fit yielded $113^{\circ}$ from anti $\left(67^{\circ}\right.$ from syn) for the $\mathrm{C}-\mathrm{C}-\mathrm{S}-\mathrm{C}$ dihedral angle and $61^{\circ}$ from syn for $\mathrm{O}-\mathrm{C}-\mathrm{C}-\mathrm{S}$ dihedral angle. The uncertainty limit corresponding approximately to three standard deviations is estimated to be $3^{\circ}$ in each of these cases. The $\mathrm{C}-\mathrm{C}-\mathrm{S}-\mathrm{C}$ dihedral angle $\left(113(3)^{\circ}\right)$ is rather close to $110.57(83)^{\circ}$ found for the corresponding dihedral angle in gauche $\mathrm{CH}_{3} \mathrm{CH}_{2} \mathrm{SCH}_{3}{ }^{13 \mathrm{~d}}$, while the $\mathrm{O}-\mathrm{C}-\mathrm{C}-\mathrm{S}$ angle of $61(3)^{\circ}$ from syn is rather typical for this kind of hydrogenbonded molecules in the gauche conformation. ${ }^{1-12}$ The rotational constants calculated employing the structural parameters of Table 7 are to be found in Table 8 .

\section{Discussion}

It is believed that the intramolecular hydrogen bond is a decisive factor for the conformational properties of 2-(methylthio)ethanol and the major cause of the $g G G$ conformation being preferred to any other form of the molecule. The hydrogen bond in the $g G G$ conformation of $\mathrm{CH}_{3} \mathrm{SCH}_{2} \mathrm{CH}_{2} \mathrm{OH}$ is of rather moderate strength, as can be inferred from the fact that the non-bonded distance be-

Table 8. Observed and calculated rotational constants ${ }^{a, b}$ for $\mathrm{CH}_{3} \mathrm{SCH}_{2} \mathrm{CH}_{2} \mathrm{OH}$ and $\mathrm{CH}_{3} \mathrm{SCH}_{2} \mathrm{CH}_{2} \mathrm{OD}$.

\begin{tabular}{|c|c|c|c|c|c|c|}
\hline \multirow[t]{2}{*}{ Constant/MHz } & \multicolumn{3}{|c|}{$\mathrm{CH}_{3} \mathrm{SCH}_{2} \mathrm{CH}_{2} \mathrm{OH}$} & \multicolumn{3}{|c|}{$\mathrm{CH}_{3} \mathrm{SCH}_{2} \mathrm{CH}_{2} \mathrm{OD}$} \\
\hline & Obs. & Calc. & Diff. / \% & Obs. & Calc. & Diff. /\% \\
\hline$A_{0}$ & 6762 & 6763 & 0.0 & 6469 & 6603 & 2.07 \\
\hline$B_{0}$ & 2315.1 & 2320.6 & 0.24 & 2280.0 & 2284.1 & 0.17 \\
\hline$C_{0}$ & 2259.6 & 2232.9 & 1.18 & 2244.2 & 2214.3 & 1.33 \\
\hline
\end{tabular}

${ }^{a}$ See text. ${ }^{b}$ Structural parameters used in the calculations are found in Table 7. 
tween the hydroxyl group hydrogen atom and the sulfur atom is approximately $34 \mathrm{pm}$ shorter than the sum of the van der Waals radii of hydrogen and sulfur ${ }^{25}$ (Table 7 ). The non-bonded distance of $321 \mathrm{pm}$ between the oxygen and sulfur atoms is almost the same as the sum of the van der Waals distances of said atoms, as revealed in the same table. The $\mathrm{O}-\mathrm{H}$ and $\mathrm{S}-\mathrm{CH}_{2}-$ bonds are about $5^{\circ}$ from being parallel. This is a favourable arrangement for electrostatic interaction between the corresponding two bond dipoles.

Interestingly, the closely related compound $\mathrm{CH}_{3} \mathrm{CH}_{2} \mathrm{SCH}_{2} \mathrm{CH}_{2} \mathrm{OH}$ is known to possess a moderately strong intramolecular hydrogen bond in carbon tetrachloride solution, ${ }^{26}$ as reflected by a shift of the $\mathrm{O}-\mathrm{H}$ stretching frequency of $92 \mathrm{~cm}^{-1}$.

The hydrogen bond in the title molecule is very similar to that in 2-mercaptoethanol. ${ }^{6}$ The conformational choices of $\mathrm{CH}_{3} \mathrm{SCH}_{2} \mathrm{CH}_{2} \mathrm{OH}$ and $\mathrm{HSCH}_{2} \mathrm{CH}_{2} \mathrm{OH}^{6}$ are also strikingly similar. In both these compounds the all-gauche conformer is strongly preferred. No other forms have been found.

The reason why the all-gauche conformers are preferred both in the case of the title compound and for 2-mercaptoethanol ${ }^{6}$ is difficult to answer. Perhaps electrons of the sulfur atom become more easily available for hydrogen bonding in this conformation than in other forms such as $g G A$. Other factors may also be of importance.

It is also of interest to compare the conformational preference of the $\mathrm{CH}_{3} \mathrm{~S}$ - group with the corresponding preference of the $\mathrm{CH}_{3} \mathrm{O}$ - group in cases where intramolecular hydrogen bonding is present. Several studies ${ }^{9}$ have shown that the methyl group is anti to the $\mathrm{C}-\mathrm{C}$ bond in the hydrogen-bonded conformer of $\mathrm{CH}_{3} \mathrm{OCH}_{2} \mathrm{CH}_{2} \mathrm{OH}$, while the rotamer in which the methyl group is gauche with respect to the $\mathrm{C}-\mathrm{C}$ bond has not been identified by $\mathrm{MW}$ spectroscopy. ${ }^{9}$ The conformational situation in $\mathrm{CH}_{3} \mathrm{OCH}_{2} \mathrm{CH}_{2} \mathrm{OH}$ is thus remarkably different from what is found in this work for $\mathrm{CH}_{3} \mathrm{SCH}_{2} \mathrm{CH}_{2} \mathrm{OH}$, where the methyl group is gauche to the $\mathrm{C}-\mathrm{C}$ bond.

Acknowledgements. The authors wish to thank Dr. Michael Schmidt of North Dakota State University for supplying the present version of GAMESS. E. U. wishes to thank VISTA (Det Norske Videnskaps-Akademi and Statoil) for continuous support. The Nansen Foundation is thanked for equipment grants.

\section{References}

1. Buckton, K. S. and Azrak, R. G. J. Chem. Phys. 52 (1970) 5652.

2. Azrak, R. G. and Wilson, E. B. J. Chem. Phys. 52 (1970) 5299.
3. Marstokk, K.-M. and Møllendal, H. Acta Chem. Scand., Ser. $A 39$ (1985) 15.

4. (a) Marstokk, K.-M. and Møllendal, H. J. Mol. Struct. 22 (1974) 301; (b) Walder, E., Bauder, A. and Günthard, H. H. Chem. Phys. 51 (1980) 223; (c) Caminati, W. and Corbelli, G. J. Mol. Spectrosc. 90 (1981) 572; (d) Kristiansen, P.-E., Marstokk, K.-M. and Møllendal, H. Acta Chem. Scand., Ser. A 41 (1987) 403.

5. (a) Penn, R. E. and Curl, R. F. J. Chem. Phys. 55 (1971) 651; (b) Penn, R. E. and Olsen, R. J. Mol. Spectrosc. 62 (1976) 423.

6. Sung, E. M. and Harmony, M. D. J. Am. Chem. Soc. 99 (1977) 5603.

7. Marstokk, K.-M. and Møllendal, H. Acta Chem. Scand., Ser. A 35 (1981) 395.

8. Szalanski, L. B. and Ford, R. G. J. Mol. Spectrosc. 54 (1975) 148.

9. (a) Buckley, P. and Brochu, M. Can. J. Chem. 50 (1970) 1149; (b) Brochu, M. and Buckley, P. Can. J. Spectrosc. 18 (1973) 165; (c) Caminati, W. and Wilson, E. B. J. Mol. Spectrosc. 81 (1980) 356; (d) Caminati, W., Cervellati, R. and Smith, Z. J. Mol. Struct. 97 (1983) 87.

10. Penn, R. E. and Buxton, L. W. J. Mol. Spectrosc. 56 (1976) 416.

11. Penn, R. E. and Olsen, R. J. J. Mol. Spectrosc. 70 (1978) 229.

12. Penn, R. E. and Birkenmeier, J. A. J. Mol. Spectrosc. 62 (1976) 416

13. (a) Sakakibara, M., Matsuura, H., Harada, I. and Shimanouchi, T. Bull. Chem. Soc. Jpn. 50 (1977) 111; (b) Oyanagi, K. and Kuchitsu, K. Bull. Chem. Soc. Jpn. (1978) 2243; (c) Hayashi, M., Adachi, M. and Nakagawa, J. J. Mol. Spectrosc. 86 (1981) 129; (d) Adachi, M., Nakagawa, J. and Hayashi, M. J. Mol. Spectrosc. 91 (1982) 381.

14. Fang, H. L. and Swofford, R. L. Chem. Phys. Lett. 105 (1984) 5.

15. Marstokk, K.-M. and Møllendal, H. J. Mol. Struct. 5 (1970) 205.

16. Wordarczyk, F. J. and Wilson, E. B. J. Mol. Spectrosc. 37 (1971) 445 .

17. Marstokk, K.-M. and Møllendal, H. Acta Chem. Scand., Ser. A 42 (1988) 374.

18. Depuis, M., Spangler, D. and Wendoloski, J. J. National Resources for Computations in Chemistry. Software Catalog, Vol. 1, Program QG01, Lawrence Berkeley Laboratory, USDOE, Berkeley 1980.

19. Binkley, J. S., Pople, J. A. and Hehre, W. J. J. Am. Chem. Soc. 102 (1980) 939.

20. Gordon, M. S., Binkley, J. S., Pople, J. A., Pietro, W. J. and Hehre W. J. J. Am. Chem. Soc. 104 (1982) 2797.

21. Smyth, C. P. Dielectric Behavior and Structure, McGraw-Hill, New York 1955, p. 244.

22. Gordy, W. and Cook, R. L. Microwave Molecular Spectra, Wiley, New York 1984, p. 229.

23. Gordy, W. and Cook, R. L. Microwave Molecular Spectra, Wiley, New York 1984, p. 329.

24. Kraitchman, J. Am. J. Phys. 21 (1953) 17.

25. Pauling, L. The Nature of the Chemical Bond, 3rd ed., Cornell University Press, New York 1960, p. 260.

26. Schleyer, P. v. R. and West, R. J. Am. Chem. Soc. 81 (1959) 3164.

Received March 24, 1988. 